\section{Bavid Pric}

The burden of respiratory disease for the NHS i substantial, with more people consulting their GP i relation to respiratory problems than for any othe group of diseases ${ }^{1}$ Furthermore $18 \%$ of emergenc ydmissions to hospitals are the result of respirator problems ${ }^{2}$ Asthma costs are of worldwide concern the cost per year for each patient with asthma $\mathrm{i}$ Sweden has been conservatively estimated at $£ 870$; i the United Kingdom, £700; and in Australia, $£ 510^{3}$ Studies have shown that the direct healthcare costs o nsthma have increased substantially in recent years fo example by nearly $40 \%$ between 1985 and 1998 in th USA $^{4}$

dWe do currently have substantial evidence that chroni respiratory disease, asthma and COPD in particular are less than optimally managed with many patients no sneeting the goals set out in guideline ${ }^{\$, 6}$, and tha gare is variably and often less than optimall delivered ${ }^{8,9}$

It is surprising therefore that little national priority unti dow has focused on chronic respiratory disease an bven at local level only about a quarter of Healt Improvement Programs include respiratory disease ${ }^{\oplus}$ One barrier to this is the difficulty in estimating th focal population burden of disease, the current cost $o$ fnanaging it and the impact on health care costs $i$ management was improved

The paper by Hazell et al in this edition of the journa gpp 61-64] may provide a useful tool in understandin these resource issues. The instrument contains questions about respiratory symptoms in whic dincreasing numbers of positive responses are associate ovith greater use of primary and secondary car nesources for respiratory disease. This may see blindingly obvious but has significant implications $\mathrm{i}$ some of its current limitations can be overcome

These limitations include

- limited current information on the sensitivity and specificity of the instrument fo chroni respiratory diseases particularly whether it rifferentiates between asthma and COPD o provides information on bot

- does the instrument capture anything of the severity of disease or simply the likelihood of its presenc

- the need for validation beyond the two practices under study

- whether the questionnaire results are affected by effective treatment although this would appear unlikely with the low level of symptoms required to trigger a response to the questions aske

- the need for modelling of health care utilisation in association with answers given and standard of nare give

- what size of population sample is required to giv reliable estimates of chronic respiratory disease and expected heath care dependent on standard of dare provide

SWith these limitations in mind, this instrument ha potential usefulness in primary care. These include

\section{dse in determining underdiagnosis and screenin for respiratory disease}

The instrument might be useful in screening for an cletermining the extent of unrecognised chroni respiratory diagnoses in a population once it is clea how predictive the measure is of asthma and als whether an amended instrument might do the same fo COPD. The measure(s) could be administered to sandom sample of patients in a locality and rate dompared with local disease registers. This woul fequire a clear understanding of the predictive nature $o$ the instrument for asthma and other chronic respirator disorders

\section{b) Determining cost of diagnosing undiagnose cespiratory diseas}

If diagnosis levels are improved, primary car nrganisations might be anxious about the impact o prescribing and management costs as well as additiona fequirement for medical resources. The current cost o bliagnosing symptomatic but undiagnosed patients wit ghronic respiratory disease might be calculated usin this measure. This would require further developmen of the instrument with some validation of the differenc m health care costs for patients with similar scores wit And without chronic respiratory diagnoses. prospective study to assess to what extent the costs o healthcare change in respect of a diagnosis triggered $b$ using these questions would therefore be helpful.

\section{c) Predicting health care utilisation for respirator disease in a populatio}

Subject to validating Hazell et als instrument on othe populations, it would take little development $\mathrm{t}$ generate a tool for predicting healthcare utilisation Shis would be especially useful for estimating cost that are currently difficult to measure beyond th gatient and practice level such as asthma dru tutilisation; in the UK current PACT data does no gifferentiate between respiratory disease dru prescribing

\section{David Price}

GPIAG Professor o

Primary Care Respirator Medicine

Đept of General Practic and Primary Care

University of Aberdeen Foresterhill Health Centre Westburn Road

Aberdeen

AB25 2AY

d.price@abdn.ac.uk

2001;10 \$56-5 


\section{Not to be reproduced without the permission of the Primary Care Respiratory Journa}

\section{Il Inderstanding variation in respiratory healt care}

There is significant variation in drug utilisation fo respiratory disease ${ }^{1}$ and in outcomes, such as deat rates from COPD ${ }^{\mathcal{L}}$ Et is unclear at the present tim to what extent this is due to variation in disease or $t$ practice, although it is likely to be a bit of both. Thi instrument would remove variation in disease fro the equation and would highlight differences and thei impact in practice.

\section{e) Comparing healthcare costs between thos offering higher quality respiratory health car}

There is some evidence that those people cared for $b$ health professionals with an interest in asthma migh have a different pattern of health care utilisation tha those without ${ }^{43,1}$ Dne of the major difficulties i nndertaking these evaluations has been populatio sariation in respiratory disease. Using thi questionnaire to verify population respiratory diseas and the methodology of capturing health care cost may clarify the associated impacts of good respirator healthcare. In fact, it may be of particular use wit she advent of increasing specialism in primary care a part of a formal evaluation of any specialist service introduced for the management of respiratory health

If the instrument can be validated in the population a targe to reliably predict burden of respiratory diseas and expected health care resource utilisation, wit bigh level disease management, it would enhance th grgument for adequate resources to support primar care management of respiratory disease

\section{Reference}

A National Asthma Campaign. Out in the Open: firue Picture of Asthma in the United Kingdo IToday. Asthma Audit 2001. The Asthma Journa dpedisalusupplement September 2001;

a. Office for Population Census and Surveys an Department of Health. 1991/2

3. National Heart, Lung, and Blood Institute National Institutes of Health. Socioeconomics. In Global Strategy for Asthma Management an Prevention: A NHLBI/WHO Workshop Report Bethesda, Md: US Dept of Health and Huma Services; 1994: chap 8. NIH publication 94-3276 f. Weiss KB, Sullivan SD. The health economics o asthma and rhinitis. I. Assessing the economi impact. IJ All Clin Immuno 2001; 10 : 3-8 15. Lagerlov P, Veninga CCM, Muskova M, et al. O behalf of the Drug Education Project (DEP) group Asthma management in five European countries gloctors knowledge, attitudes and prescribin behaviour. Eur Respir 2000; $\mathbf{3}$ : 25-29

6. Nicklas RA. National and international guideline for the diagnosis and treatment of asthma. Curr Opi Pulm Med 1997; 3: 51-55

R. Price D, Ryan D, Pearce L, Bride F. The AI study: asthma in real life. Asthma ;1999 4:74-78 8. Price DB, Wolfe S. Patient's use and views on th service provided. Asthma 2000 5:141-144

.9. Rabe KF, Vermiere PA, Sariano JB, Maier WC Clinical management of asthma in 1999: the Asthm Insights and Reality in Europe (AIRE) study. $E u$ Respir J 2000; 6 : 802-807

10. Peel A. Asthma as a Local Priority in England Asthma ;1999 3: 137-138

11 1. Ferguson J J, Field J. Trends in prescribing fo asthma by general practitioners in England. Asthma 1999; 4: 158-164

12. Office of National Statistics 1994

h3. Jones K. Impact of an interest in asthma o prescribing costs in general practice \ual Healt Car 1992; $1(2$ : 110-3

14. Price D. Inhaled Steroid Prescribing Over Seve ears in a General Practice and Its Implications. Eu Resp.J. 1995 :463s 